\title{
Evaluation of Tourist Attractions in Borujerd County with Emphasis on Development of New Markets by Using Topsis Model
}

\author{
Mohammad Taghipour ${ }^{1, *}$, Jahangir Ahmadi Sarchoghaei \\ ${ }^{1}$ Department of Industrial Engineering, Science and Research Branch of Islamic Azad University, Tehran, Iran \\ ${ }^{2}$ Department of Tourism Management, Non-Profit Institution of Higher Education, Aba- Abyek, Qazvin, Iran
}

Email address:

mohamad.taghipour@srbiau.ac.ir(M. Taghipour),j.ahmadi2011@gmail.com (J. A. Sarchoghaei)

\section{To cite this article:}

Mohammad Taghipour, Jahangir Ahmadi Sarchoghaei. Evaluation of Tourist Attractions in Borujerd County with Emphasis on Development of New Markets by Using TOPSIS Model. Science Journal of Business and Management. Vol. 3, No. 5, 2015, pp. 175-189.

doi: $10.11648 /$ j.sjbm.20150305.16

\begin{abstract}
This research aims to identify tourist attractions in Borujerd County in order to develop new tourism markets in Lorestan province of Iran. For that purpose and with the use of GIS, parameters such as slope, aspect, elevation, precipitation, land use, topography, and landform geology are separately studied and digital maps for each feature are created. Through interviews with experts and with regard to those parameters, ecotourism activities in the region are identified; and the final maps of the zones suitable for these activities are produced. These activities have been analyzed using TOPSIS multi-criteria decision model and based on marketing factors. TOPSIS analysis defines the order of preference of the region's tourism activities as ecotourism, rural tourism, hiking, mountaineering, and winter sports respectively. In other words, the mentioned activities have higher marketing priority.
\end{abstract}

Keywords: Marketing, New Tourism Markets, Natural Attractions, Rural Tourism, Geographic Information System (GIS), Borujerd County

\section{Introduction}

Tourism is an ancient phenomenon in human societies which through time has evolved into its current technical, economic, social, and ecological status [1]. As an industry, it makes up for almost 10 percent of global income, and as an occupation it provides jobs for one-tenth of global workforce. Due to its economic value as well as cultural and social impacts, tourism industry is an important matter to be involved with [2].

Iran has a rich heritage of historical, cultural, natural and ethnological attractions and has a great potential for development of tourism industry. Introduction of natural attraction in order to identify potential markets can be an effective step towards sustainable tourism in the region. Tourism marketing has developed new concepts regarding various marketing skills and is connected to modern technology via geographic information system. However the traditional methods of marketing have never been denied by tourism marketers who use tourism marketing by GIS as a combination of modern and traditional methods

\section{[3].}

Located at the East side of Zagros Mountains, Borujerd County has a fine climate, vast water resources, and an untouched natural environment and can be an appropriate market for tourism. Of course this issue requires the proper understanding and evaluation of the potentials of this county. For this purpose this research use GIS to identify ecological capacities of this region, extract the suitable tourism activities based on those capacities, determine the domain of each activity, and then use TOPSIS model and marketing criteria to assess and prioritize the potentials for tourist attraction. The criteria considered for marketing are:

- Safety and security of the region for each ecotourism activity

- Presence of adequate information and expert guides for each are and activity

- Tourists' general opinion about the county

- Roads and accessibility of each area

- The ability to acquire investments in each domain and area in order to develop the market

- The extent of available welfare and recreational 
accommodation for each activity

In this research, with the use of hierarchical analysis we try to answer these questions: can we reach appropriate solutions to develop and expand tourism in Borujerd? And can we propose appropriate and practical plans for that purpose?

\section{Introduction of the Studied Region}

Lorestan province is a politically, economically, and demographically important Iranian province and a center for tourism industry. Yet it sends out mode tourists than it receives in. Borujerd is a Western Iranian county. It is located in Zagros Mountains and its capital is Borujerd City. The county of Borujerd is bound from north to Malayer\&Nahavand in Hamedan province, from east to Shazand County in Markazi province, from South to Dorood County, and from west to the counties of Khorramabadand Delfan. Borujerd County lies between $33^{\circ} 36^{\prime} \mathrm{N}$ and $34^{\circ} 6^{\prime} \mathrm{N}$, and between $48^{\circ} 27^{\prime} \mathrm{E}$ and $49^{\circ} 27^{\prime} \mathrm{E}$.

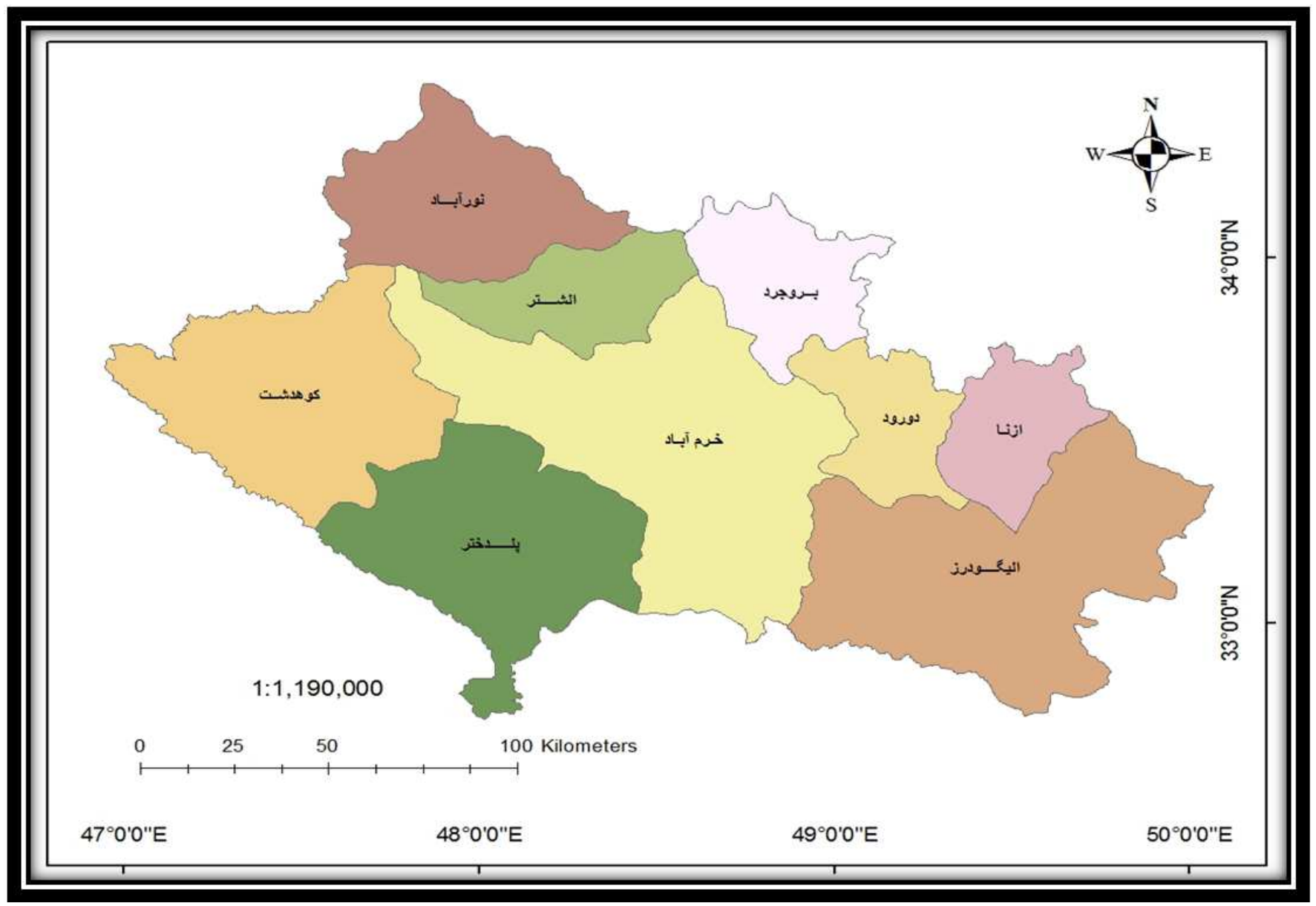

Picture 1. Location of Borujerd County within Lorestan province.

\section{Identification of Ecological Resources}

To evaluate environmental capacity to tourism development and marketing, first every environmental element affecting tourism such as topography, geographical aspect and orientation, slope, landform, land use, and conditions of climate, precipitation, and temperature should be evaluated and classified. Then with the combination of the identified elements and through systematic evaluation, a pattern for productivity of the environment is produced using which different areas and regions can be orderly ranked and classified in terms of tourism capacity and specific use.

\section{Evaluation of Ecological Capability}

Evaluation of ecological capability refers to the appraisal and evaluation of each homogeneous zone in a land for different types of use [4].

Common types of recreation in Iran and other parts of world are divided into two major categories based on the extent of land/environmental development they require.

Intensive recreation: this category of recreation requires further environmental development. It includes activities such as swimming, Ski, camping, bicycle riding, and cultural sightseeing.

Extensive recreation: this category refers to activities which do not require any land/environmental development such as mountaineering, hunting, or activities which require little development such as fishing, safari, horse riding, and 
watching animals in their natural habitat.

On that basis, a tourism ecological model for intensive and extensive recreation has been prepared which will be presented separately.

\section{Ecological Model for Intensive Recreation}

\subsection{First Class}

Climate: mean temperature in the season of spring and summer is $21-25^{\circ} \mathrm{C}$. Number of sunny days per month in the season of spring and summer is more than 15 days.

Water: 40 to 150 liters per day per person.

Slope: zero to 5 percent.

Geographical aspect: eastern (summer), southern (winter).

Soil texture: loam.

Soil drainage: complete

Soil fertility: moderate to good

Soil structure: semi-developed to fully-developed with medium granules

Soil depth: deep

Parent rock: granite, sand hills (humid climate), flood basalt, alluvium (continental plate alluvial deposit).

Vegetation density: 40 to 80 percent

Species composition: mostly monocotyledons

\subsection{Second Class}

Climate: mean temperature in the season of spring and summer is $21-30^{\circ} \mathrm{C}$. Number of sunny days per month in the season of spring and summer is more than 7-15 days.

Water: 12 to 40 liters per day per person.

Slope: 5 to 15 percent.

Geographical aspect: northern (summer), western (winter).

Soil texture: sand, loam clay, clay loam.

Soil drainage: poor to medium.

Soil fertility: moderate.

Soil structure: semi-developed semi-medium to large granules

Soil depth: medium to deep

Parent rock: sandstone, limestone, tuff, inter-strata flows, schist, flood valleys, and alluvial fan.

Vegetation density: 20 to 40 percent

Species composition: mostly mono-cotyledons and dicotyledons in almost equal proportion.

\subsection{Unsuitable}

Water: less than 5 liters per day per person.

Slope: more than 15 percent.

Geographical aspect: southern and western (summer and spring), eastern and northern (winter).

Soil texture: heavy clay, hydromorphic soil.

oil drainage: incomplete.

oil fertility: extremely poor.

Soil structure: very small granules.

Vegetation density: more than 80 percent
Species composition: mostly di-cotyledons, woody plants or thorn bushes, or slow-growing plants [5].

\section{Ecological Model for Extensive Recreation}

\subsection{First Class}

Climate: same as that of intensive recreation (first class).

Water: 5-12 liters per day per person.

Slope: zero to 25 percent.

Soil and geological condition: same as first class intensive recreation (these conditions are important only for building pavements and dirt roads, otherwise they are irrelevant to extensive recreation).

Other parameters: of little importance.

\subsection{Second Class}

Climate: same as that of intensive recreation (second class).

Water: about 5 liters.

Slope: 25 to 50 percent.

Soil and geological condition: same as second class intensive recreation (these conditions are important only for building pavements and dirt roads, otherwise they are irrelevant).

Other parameters: of little importance.

\subsection{Unsuitable}

Slope: 50 percent (with the exception of mountaineering, this condition makes the area unsuitable for any activity).

When evaluating ecological capabilities for tourism, one must bear in mind that not all parameters in the ecological model have the same weight. The ranking order of parameters in terms of importance is as follows:

1- Slope 2- Soil and rock condition 3- Geographical aspect 4- Water 5- Vegetation 6- Climate

This order signifies that if for example the slope of the environmental unit was not suitable for recreational purposes, then the unit will automatically be dismissed and other parameters would not be evaluated at all; also if the slope was appropriate but the soil and rock conditions were not suitable for recreational purposes, then other parameters would not be evaluated [5]. On this basis, the following maps have been produced.

With the use of layers of information regarding soil, rock, geographical aspect, vegetation and climate which were obtained in the section of intensive recreation, and using a slope map designed with regard to first \& second class of extensive recreation, the map of suitable zones for first and second class extensive recreation has been produced by integration of different layers. 


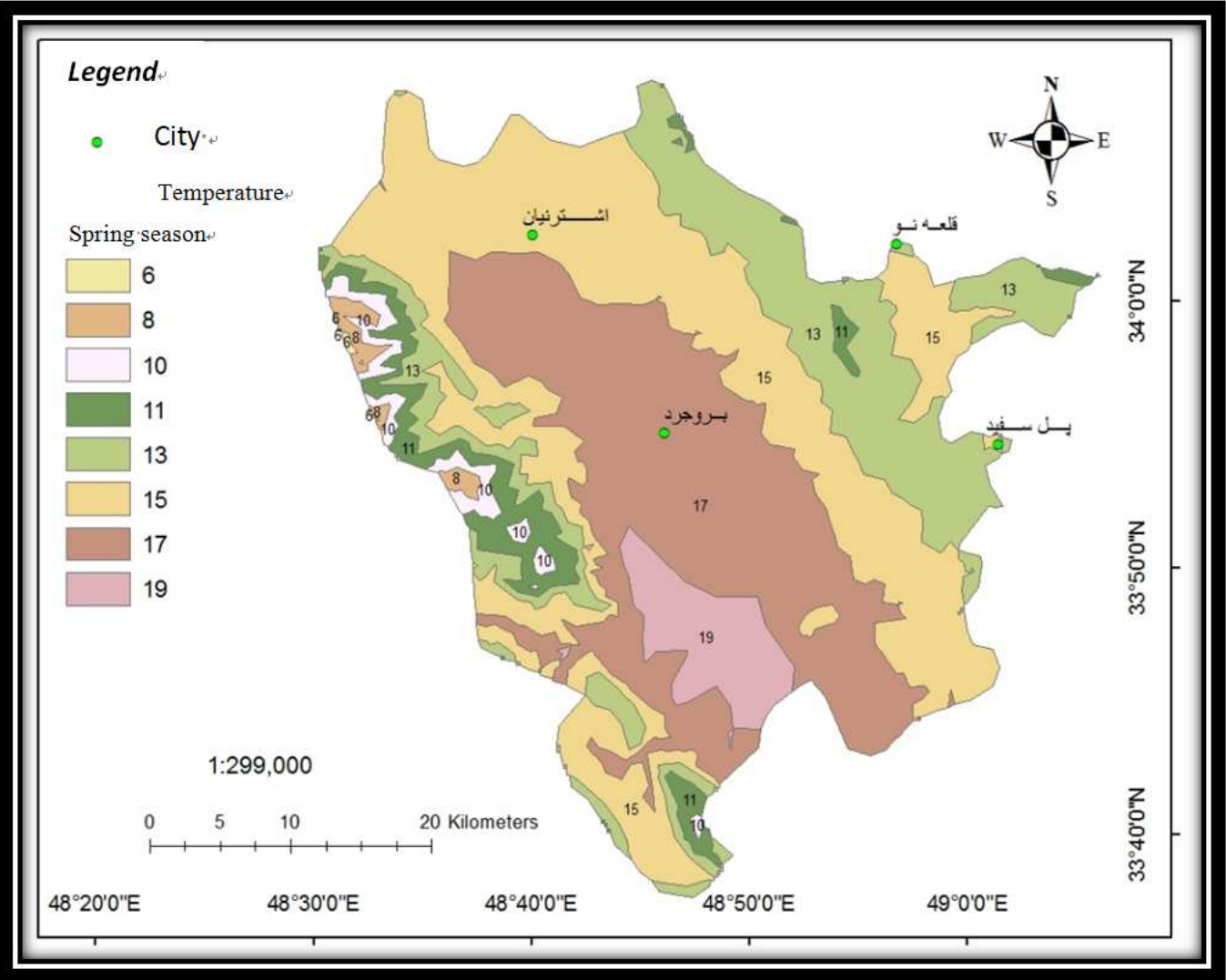

Picture 2. Temperature map of the area in spring season for first and second class intensive recreation.

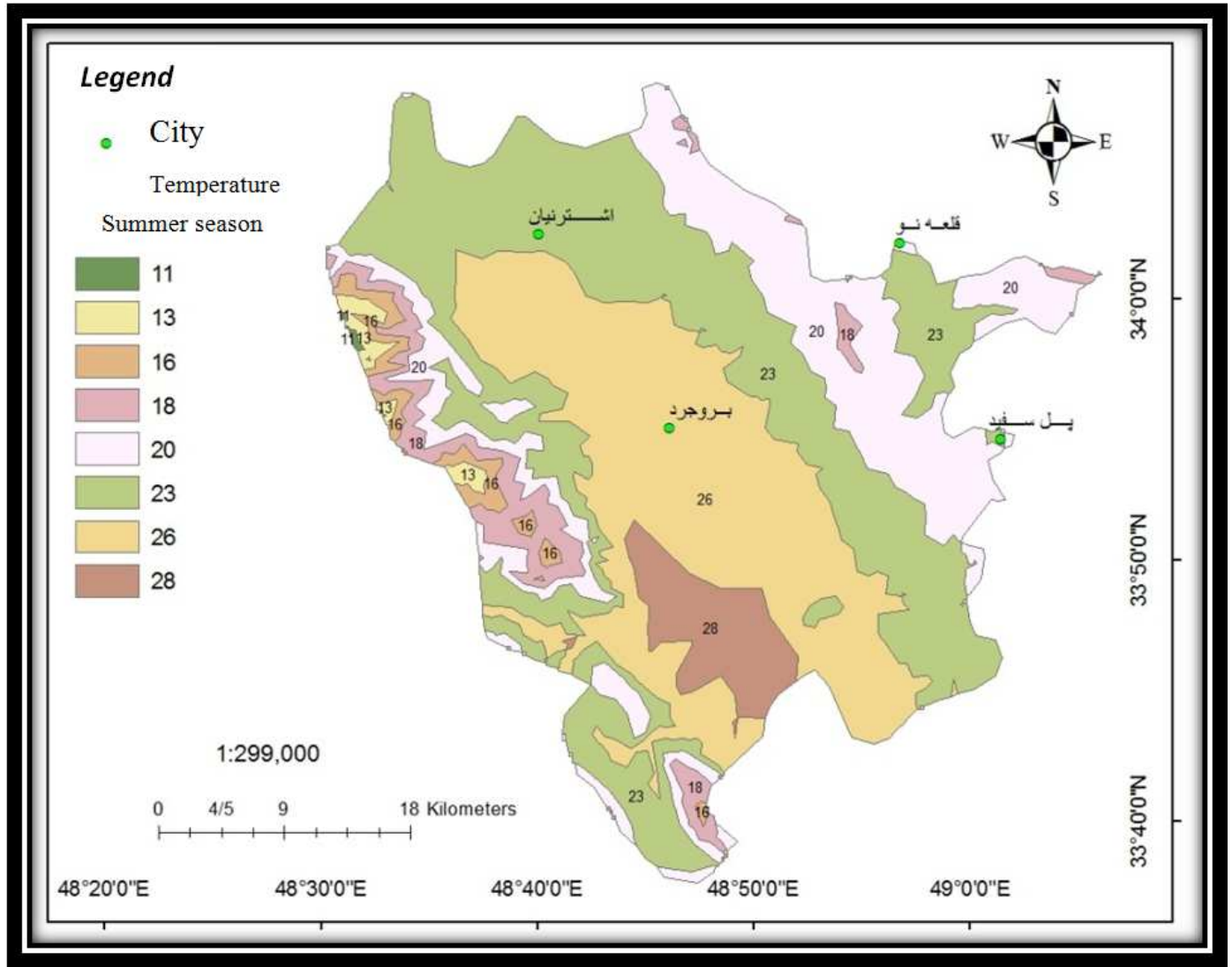

Picture 3. Temperature map of the area in summer season for first and second class intensive recreation. 


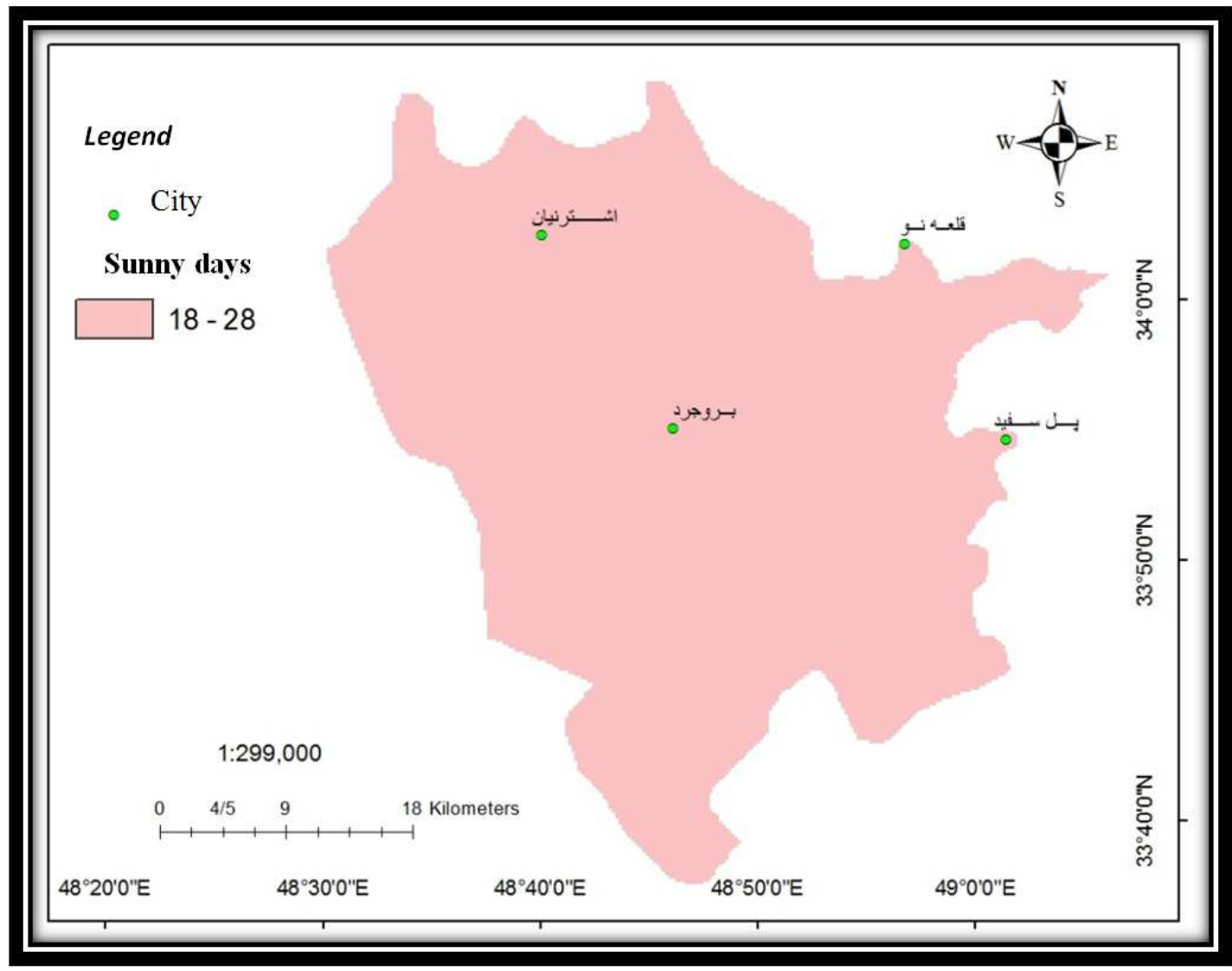

Picture 4. Map of the number of sunny days per month in Borujerd County for first \& second class intensive recreation.

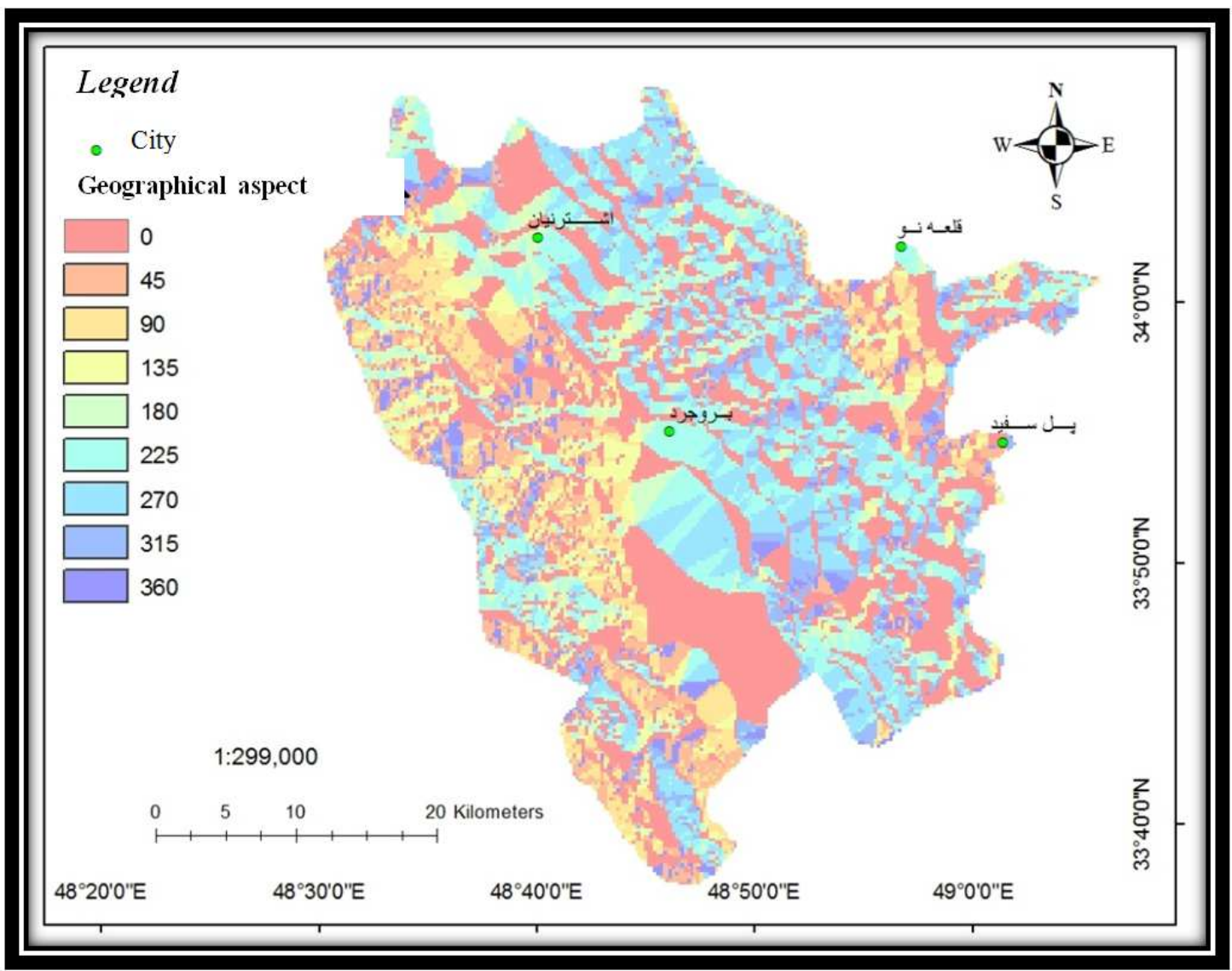

Picture 5. Maps of Borujerd County geographical aspect for first \& second class intensive recreation. 


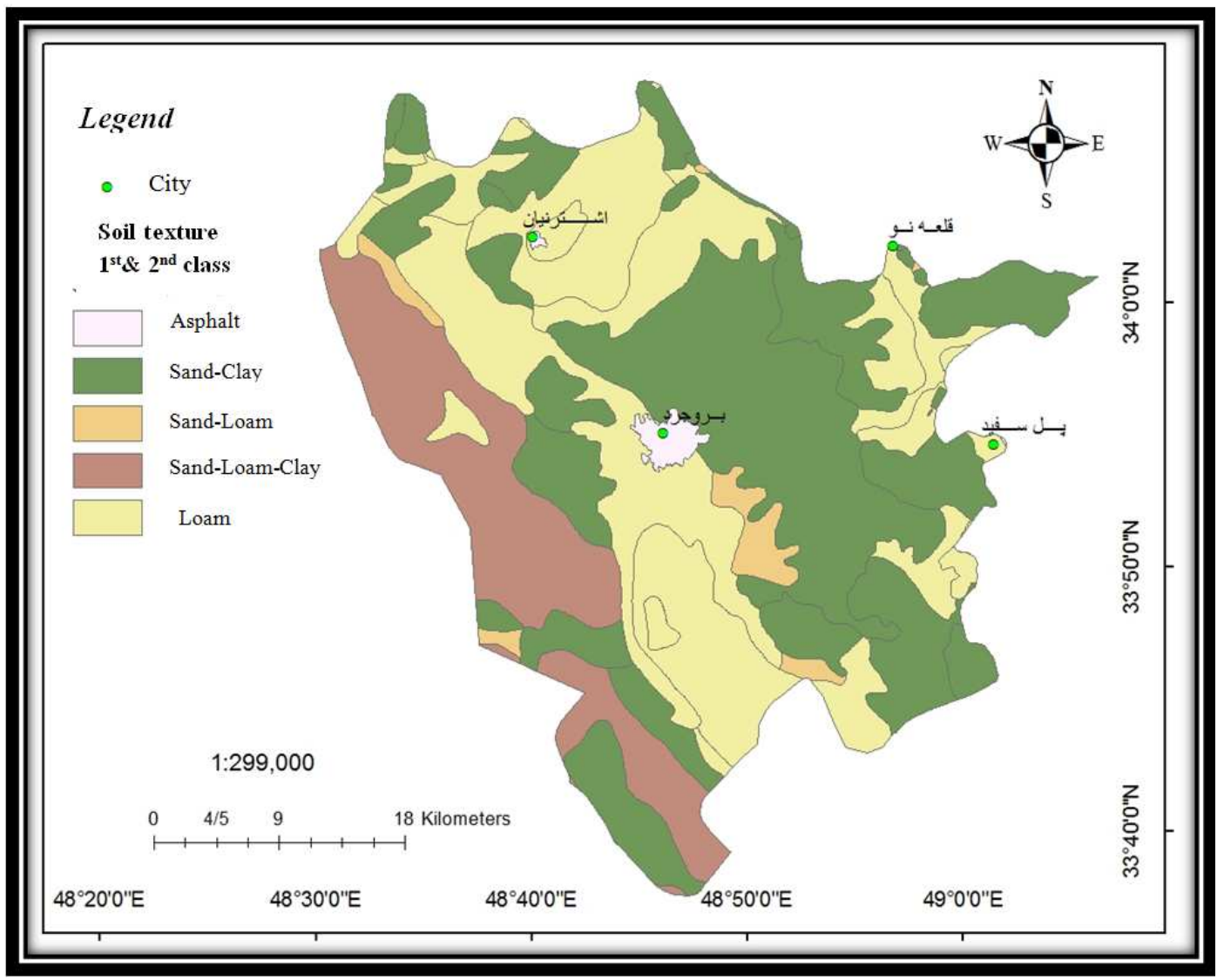

Picture 6. Soil texture map of Borujerd County for first \& second class intensive recreation.

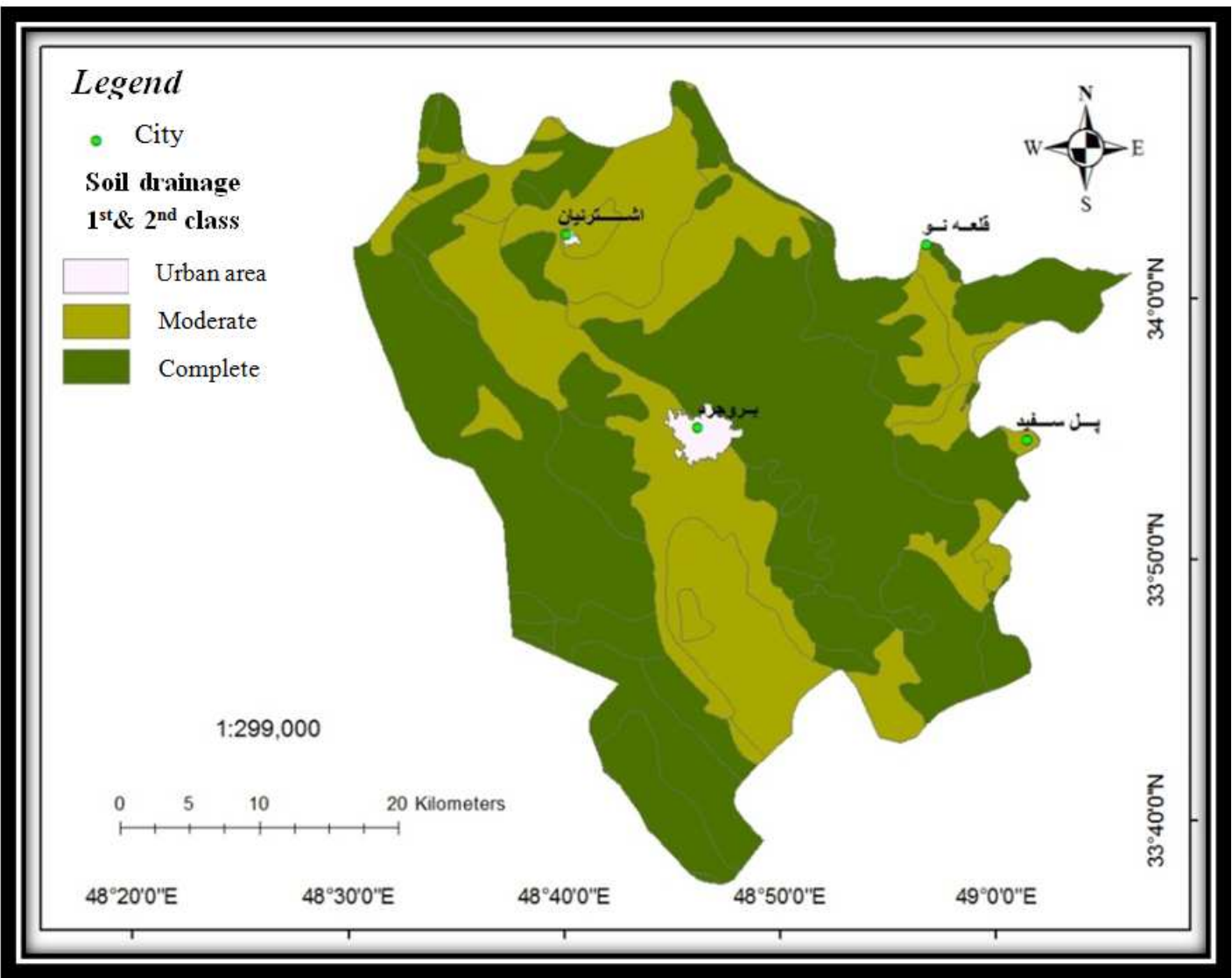

Picture 7. Soil drainage map of Borujerd County for first \& second class intensive recreation. 


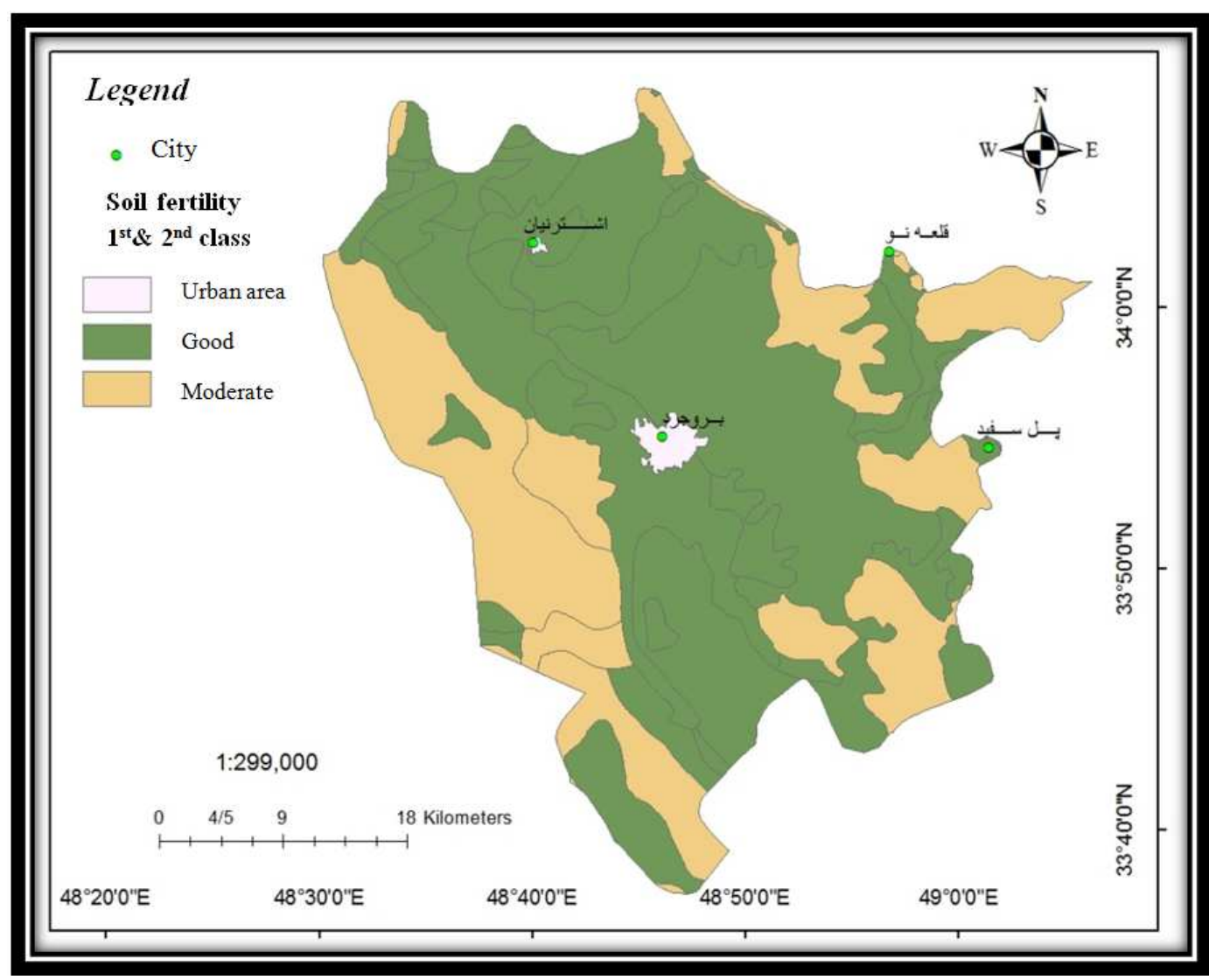

Picture 8. Soil fertility map of Borujerd County for first \& second class intensive recreation.

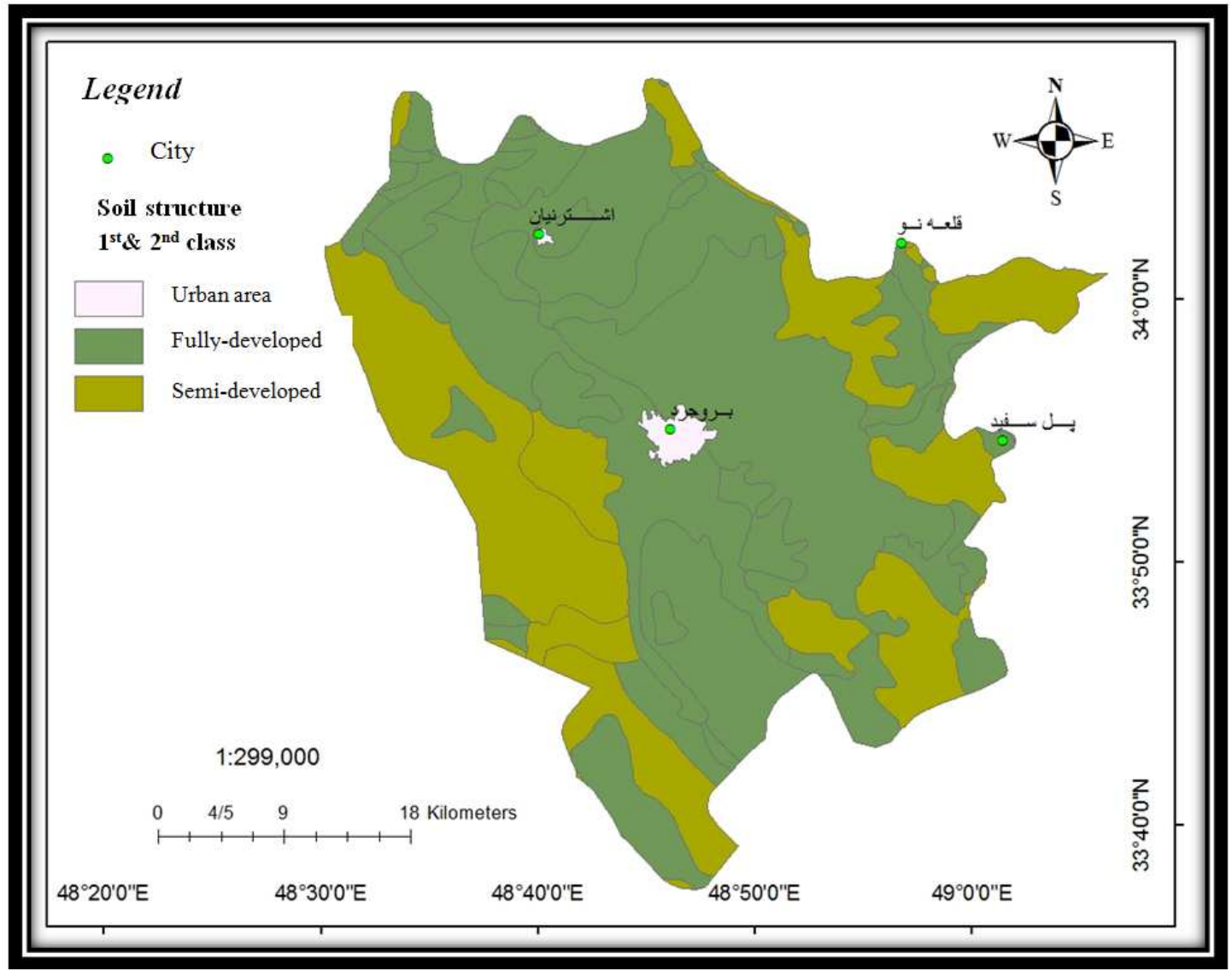

Picture 9. Soil structure map of Borujerd County for first \& second class intensive recreation. 


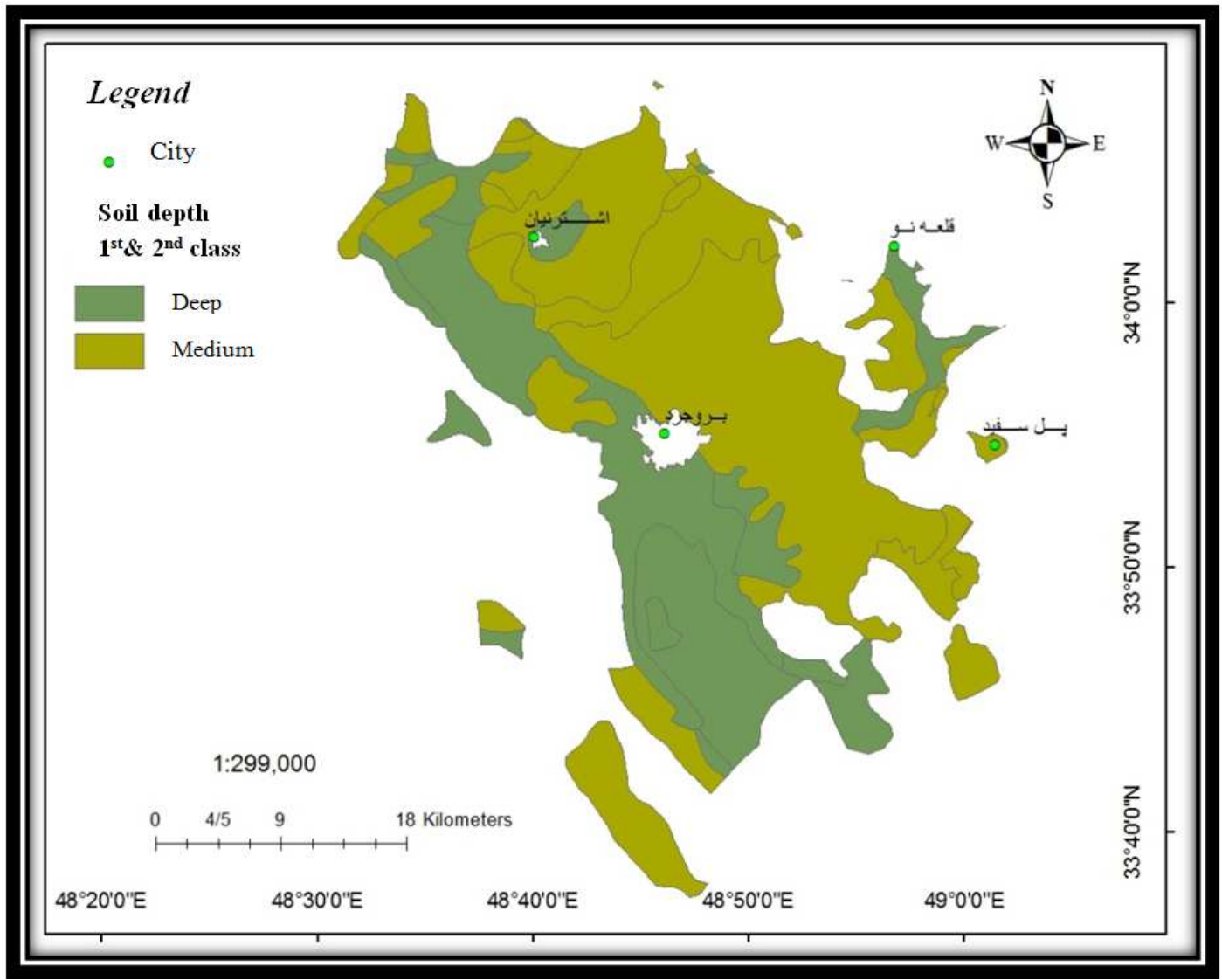

Picture 10. Soil depth map of Borujerd County for first \& second class intensive recreation.

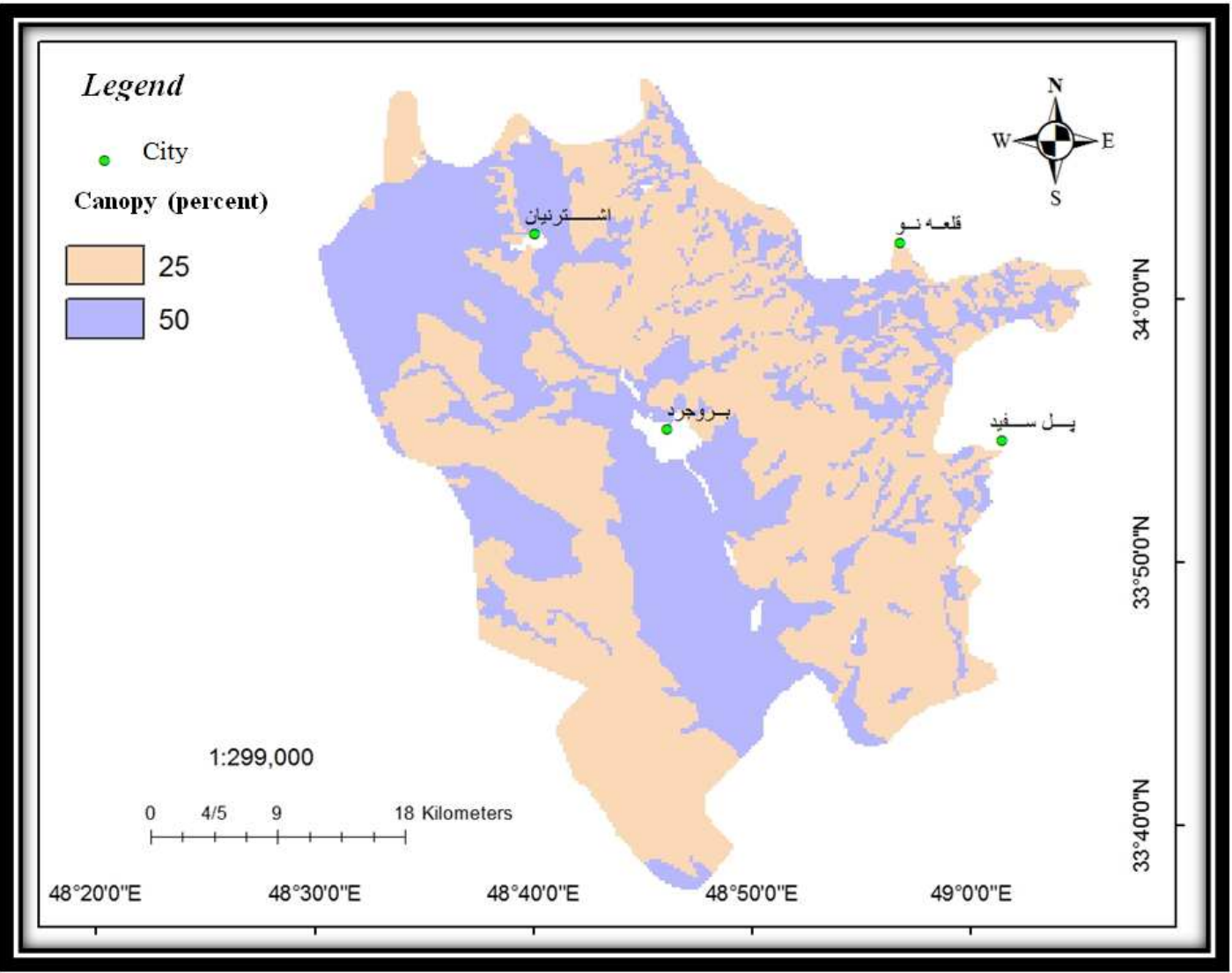

Picture 11. Vegetation density map of Borujerd County for first \& second class intensive recreation. 


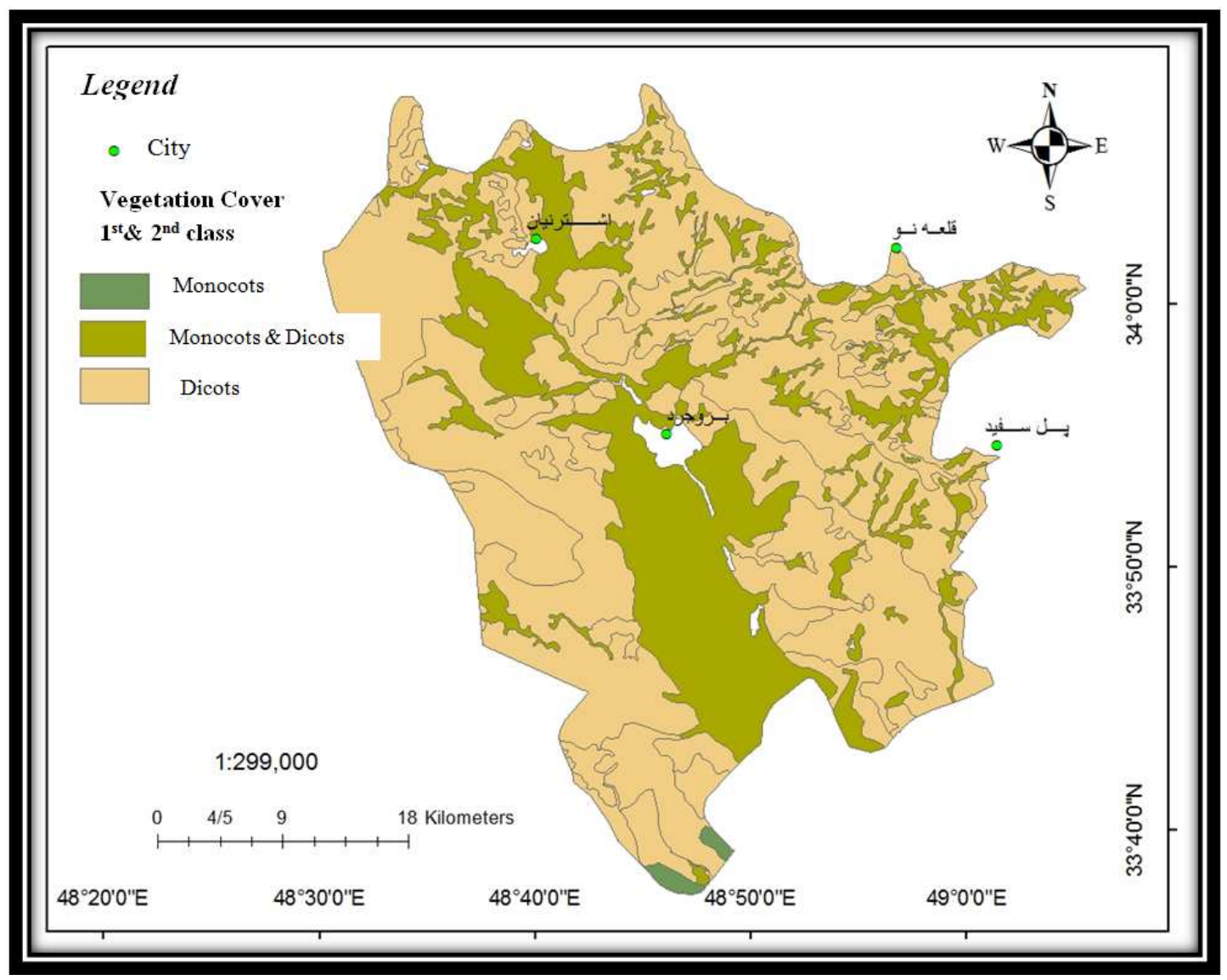

Picture 12. Vegetation ecology map of Borujerd County for first \& second class intensive recreation.

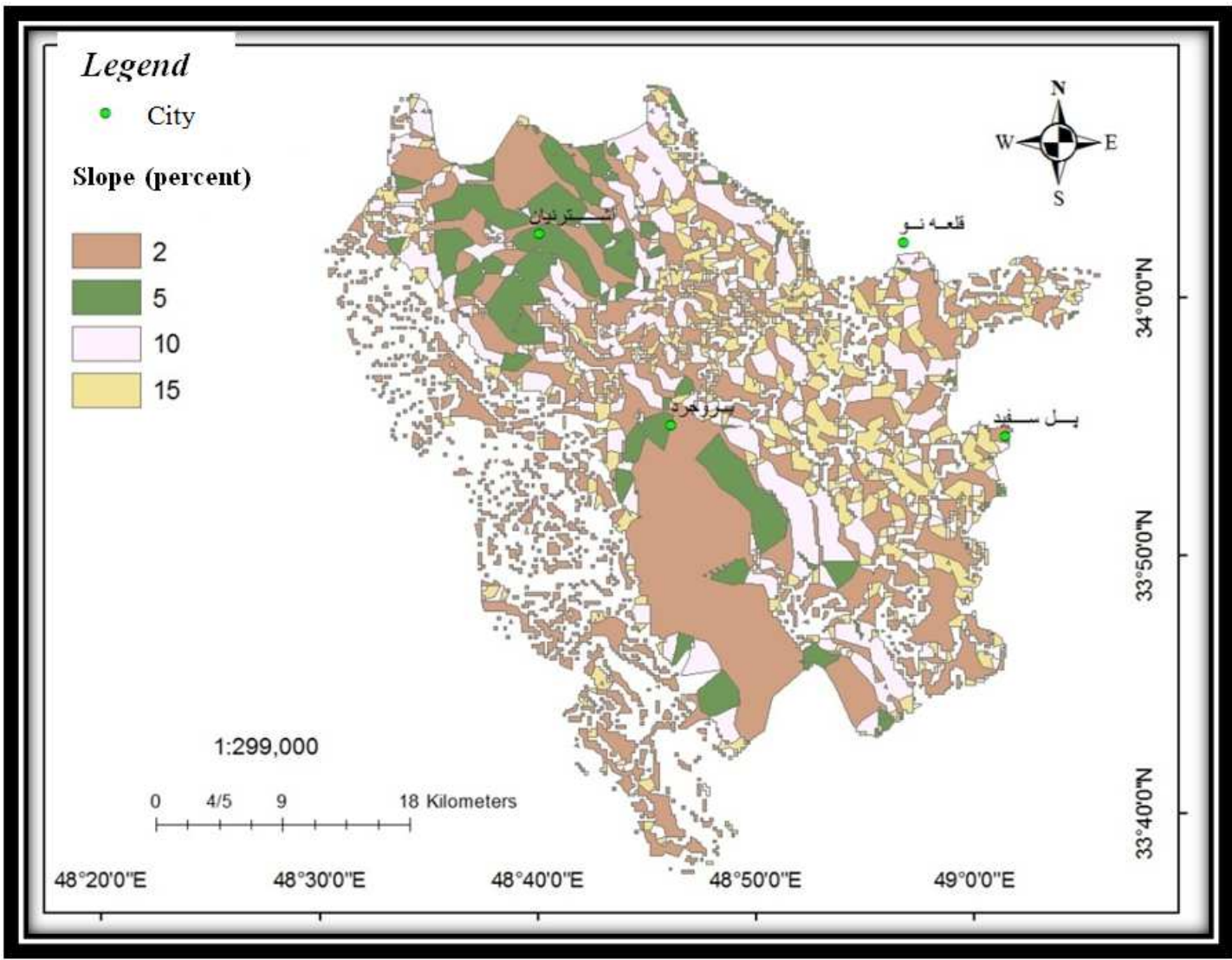

Picture 13. Slope map of Borujerd County for first \& second class intensive recreation. 


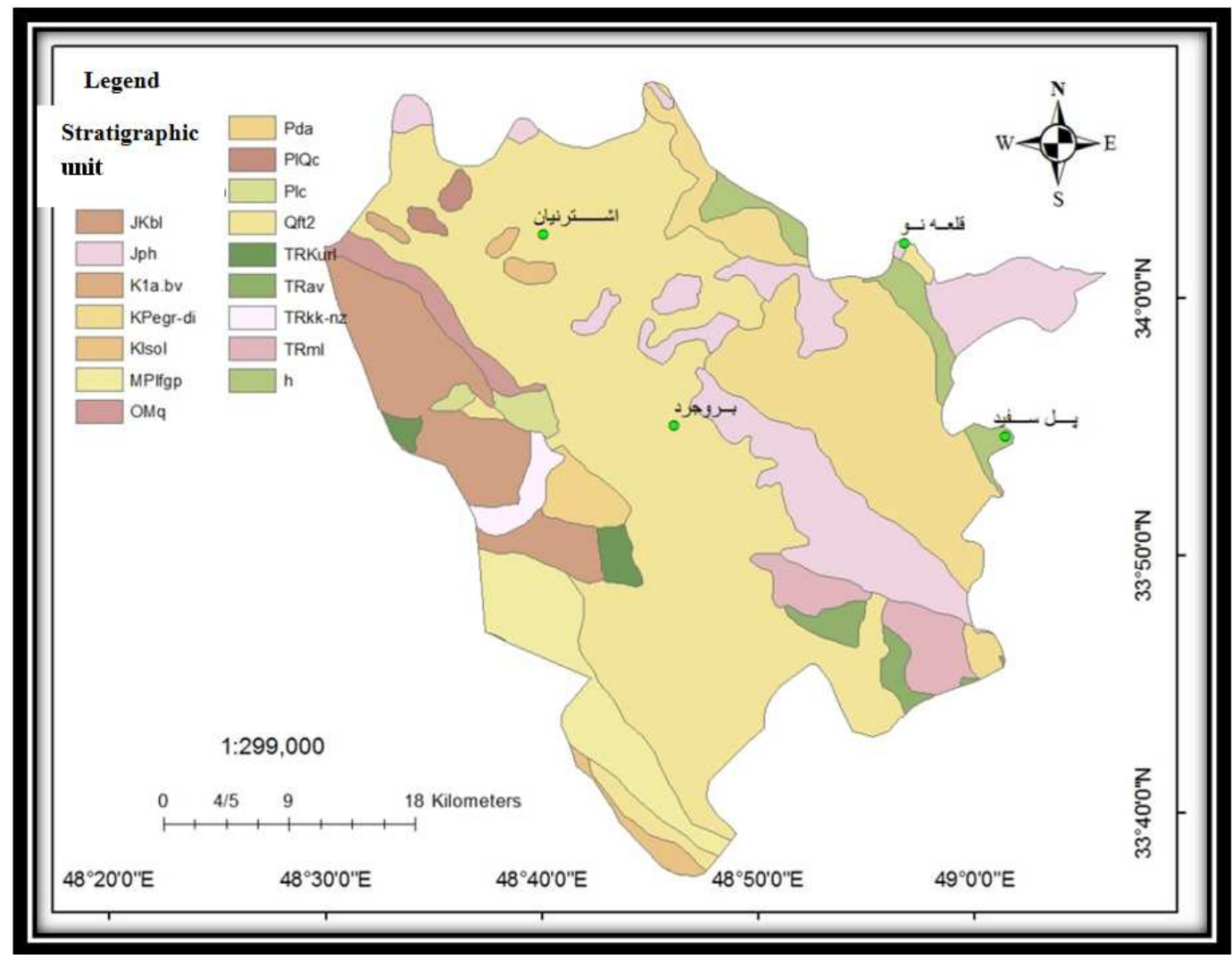

Picture 14. Geological map of Borujerd County for first \& second class intensive recreation.

By integration of the maps displayed above, the following map of suitable zones for intensive recreation has been created:

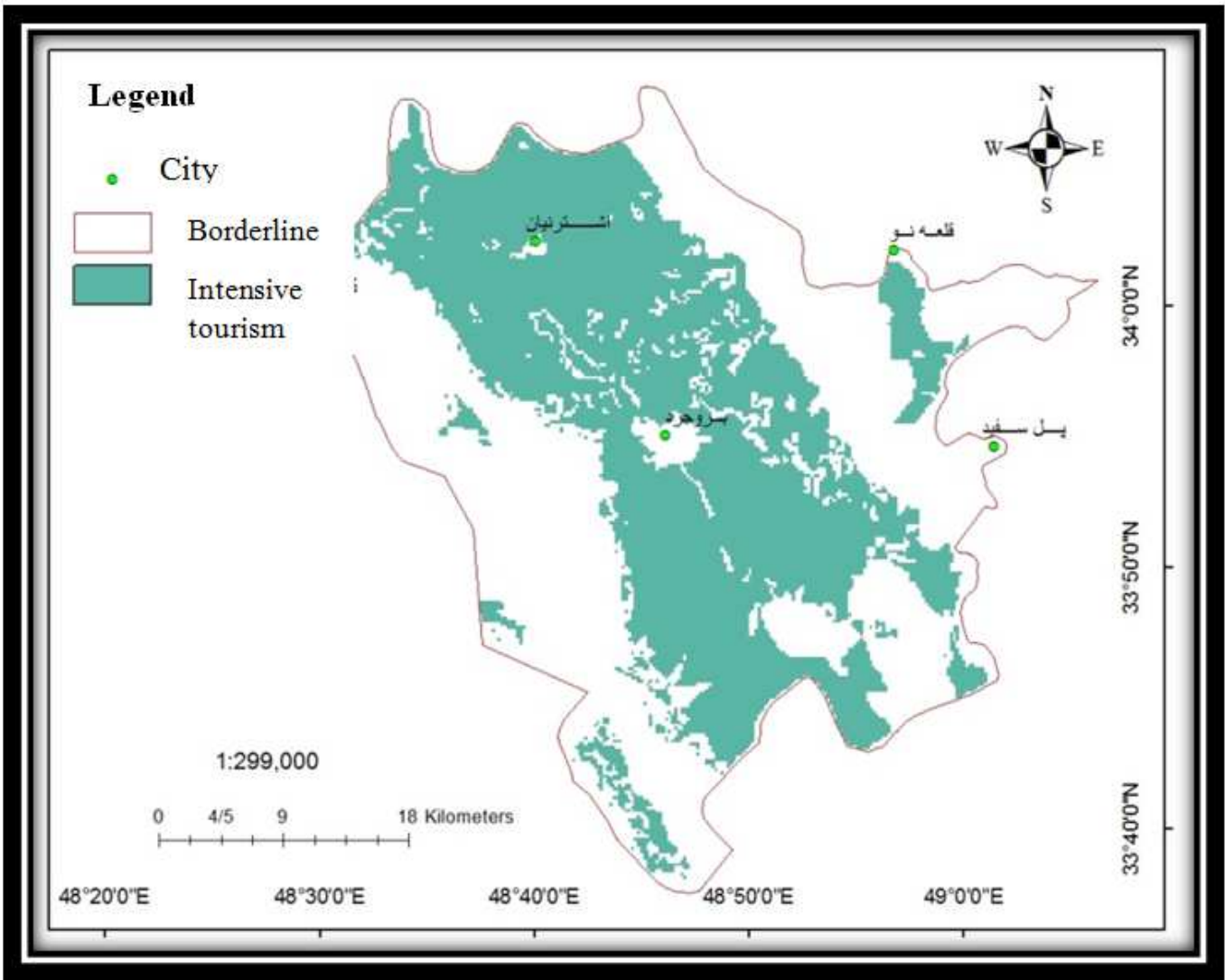

Picture 15. Map of suitable tourism zones for first \& second class intensive recreation. 


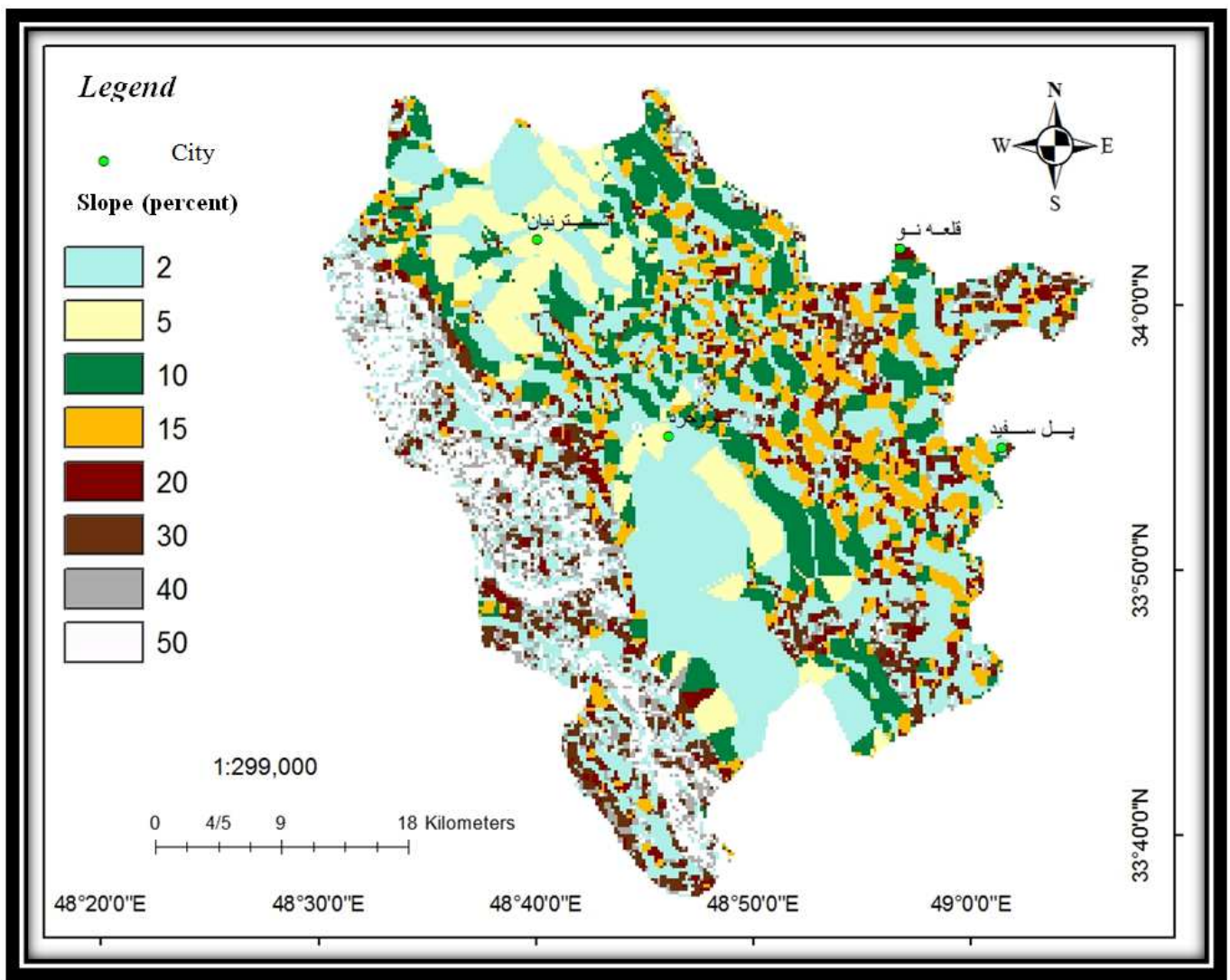

Picture 16. Slope map of Borujerd County for first \& second class intensive recreation.

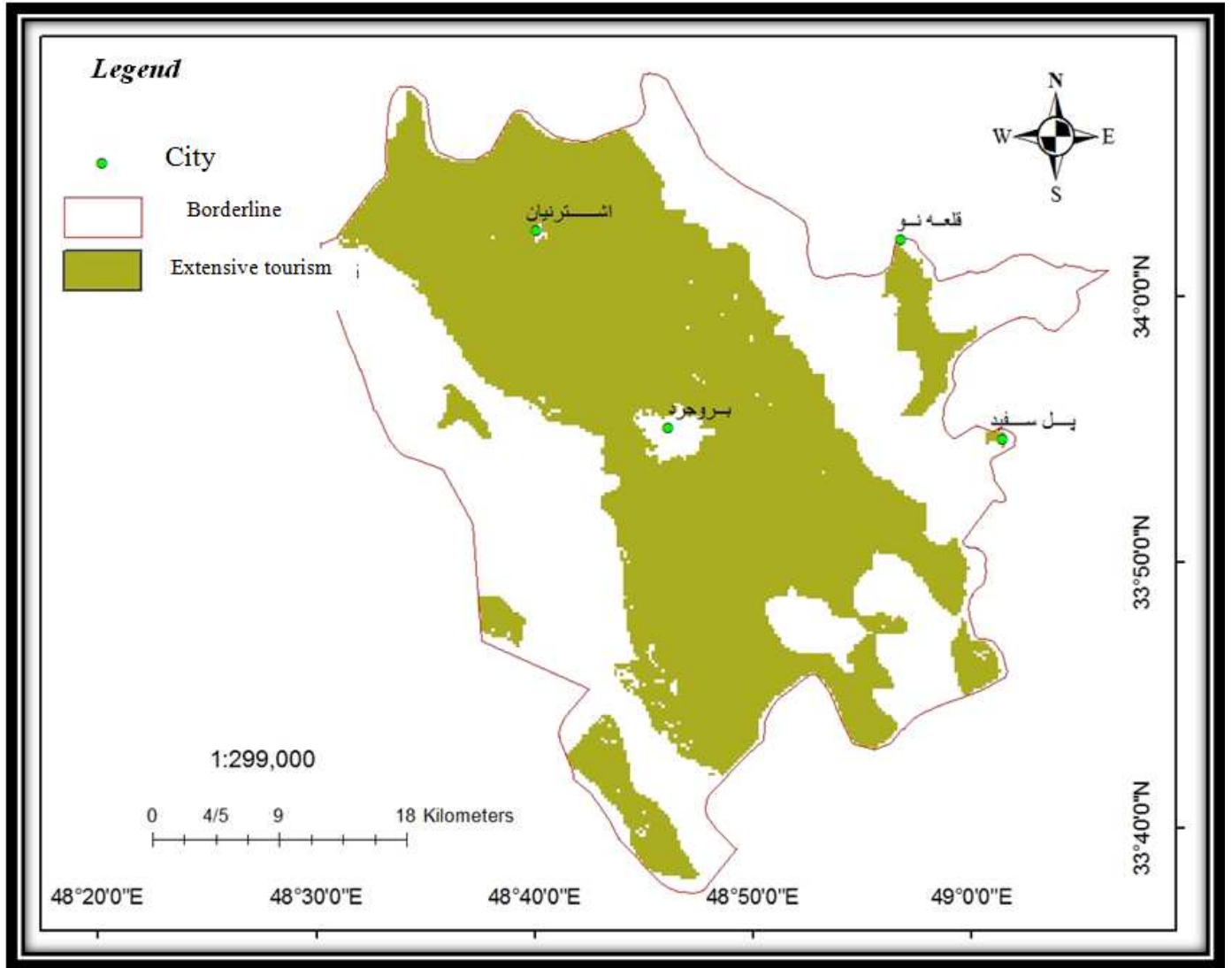

Picture 17. Map of suitable tourism zones for extensive recreation. 


\section{Data Collection and Analysis}

Correct selection of suitable areas for development of new markets requires accurate identification and prioritization of capabilities and capacities of the region. For that purpose, after analysis of the digital maps of the county, ecotourism capabilities of the area were identified. The tourist activities deemed suitable for this county are: natural sightseeing, winter sports, mountaineering, and hiking.

Table 1. Information layers used for identification of tourism activities.

\begin{tabular}{lllll}
\hline \multirow{2}{*}{ Information layers } & Type of tourism activity & & & Winter sports \\
\cline { 2 - 5 } & Mountaineering & Hiking & Natural sightseeing \\
\hline Elevation map & $*$ & $*$ & $*$ & $*$ \\
Slope map & $*$ & $*$ & & $*$ \\
Land use map & & & $*$ & $*$ \\
Temperature map & & & $*$ & $*$ \\
Climate map & & & $*$ \\
Aspect map & & & & $*$ \\
\hline
\end{tabular}

Table 2. Indicators and factors used for integration of information layers for each tourism activity.

\begin{tabular}{ll}
\hline Type of tourism activity & Indicator \\
\hline Mountaineering & Slope: more than $50 \%$ levation: higher than 2700 meters \\
Hiking & Slope: between $40 \%$ and $60 \%$ levation: between 2400 to 2700 meters \\
Winter sports & Slope: between $40 \%$ and $80 \%$ levation: higher than 2300 meters Aspect: between $225^{\circ}$ to $360^{\circ}$ \\
Natural sightseeing & Temperature: higher than $10^{\circ} \mathrm{C}$ lope: between $2 \%$ and $50 \%$ levation: between 1200 to 2100 meters 11 kinds of \\
Rural tourism & land use except urban and industrial l kinds of climates \\
\hline
\end{tabular}

\section{Suitable Zones for Mountaineering}

Borujerd County lies on a vast jagged area of Zagros Mountains. This limestone field preserves snow in its slopes throughout the cold part of the year. The melting of snow creates numerous water springs at the foot of these limestone slopes. Due to mountainous situation of this county and its numerous peaks, mountaineering activities have a good livelihood in this area. Mountaineering falls into the category of sport tourism because sports and athletic contests are the main purpose of tourists in such activities [6].

Mountaineering as a recreation is mostly an amateur activity. Enthusiasts of every age pursue this activity. Mountaineering as a professional activity however is practiced in different branches i.e. rock climbing, stone summit climbing, mountain climbing etc.

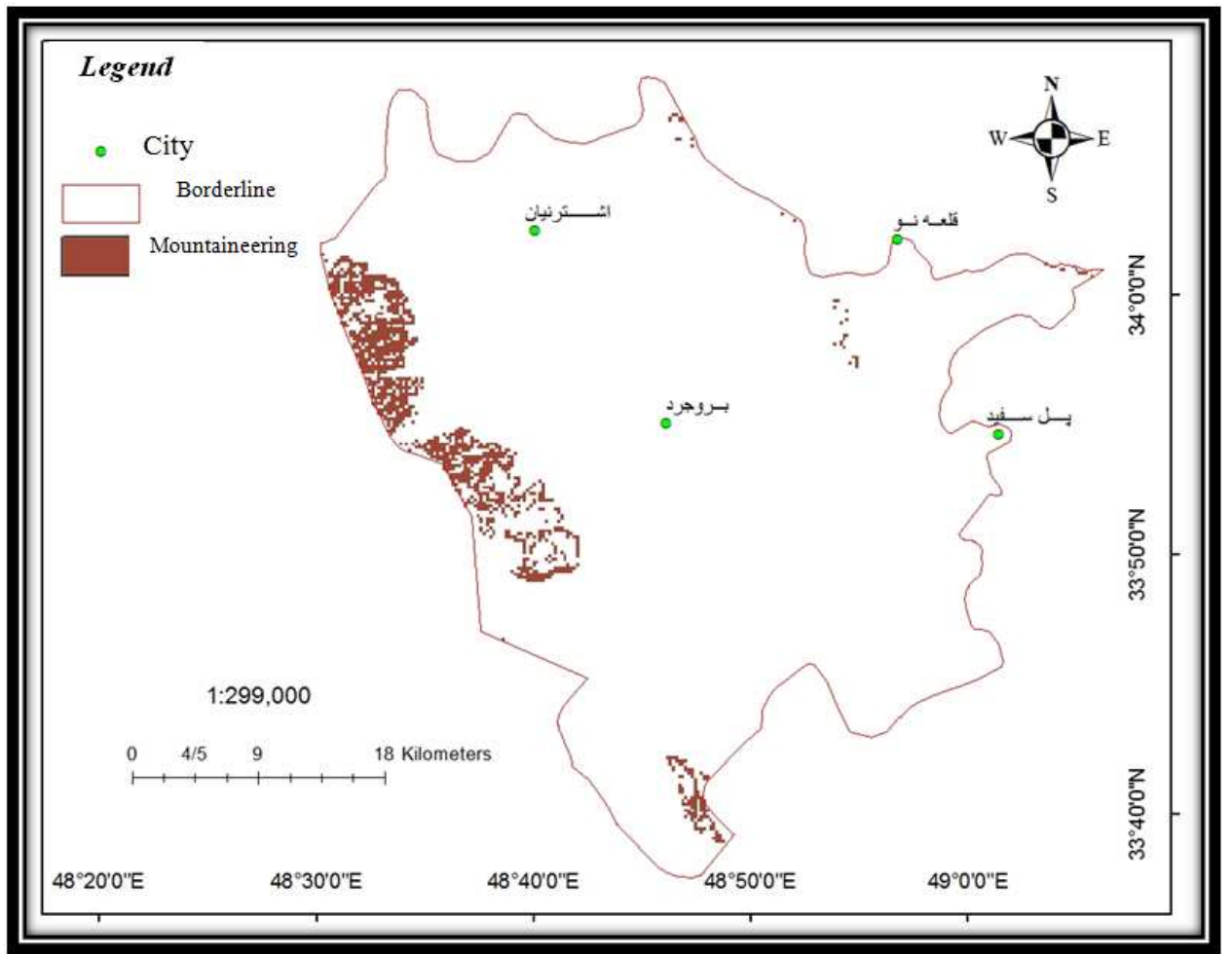

Picture 18. Map of suitable zones for mountaineering in Borujerd County. 


\section{Suitable Zones for Hiking in the Mountains}

Hiking activities should be done in an appropriate elevation so that it would be available to all individuals who wish to walk about and see the attractions of the area. Based on the factors and indicators mentioned in the tables, suitable zones for hiking and natural sightseeing are mapped in the picture 19 .

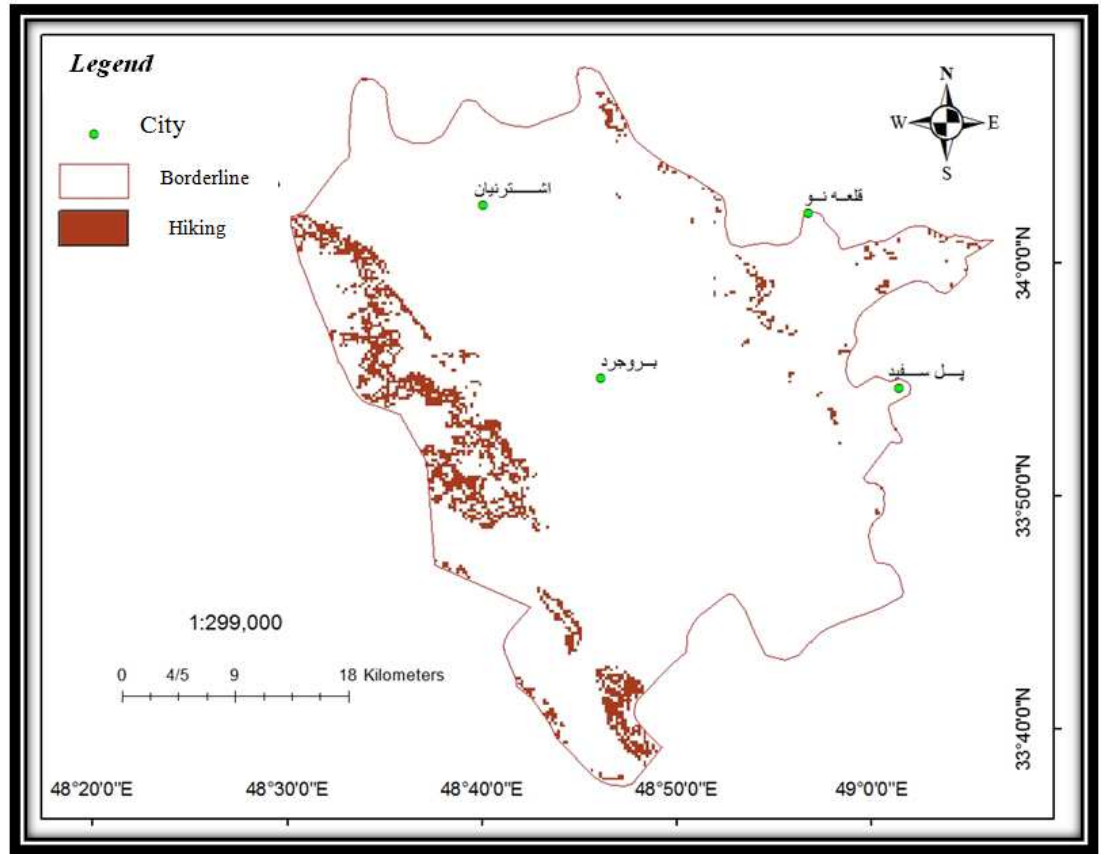

Picture 19. Map of suitable zones for hiking in Borujerd County.

\section{Suitable Zones for Winter Sports (Skiing \& Snow-Craft)}

Based on the factors and indicators mentioned in the tables, suitable zones for such activities are located in north and east of the county. Due to their heavy accumulation of snow and appropriate steepness these areas are suitable for winter sports.

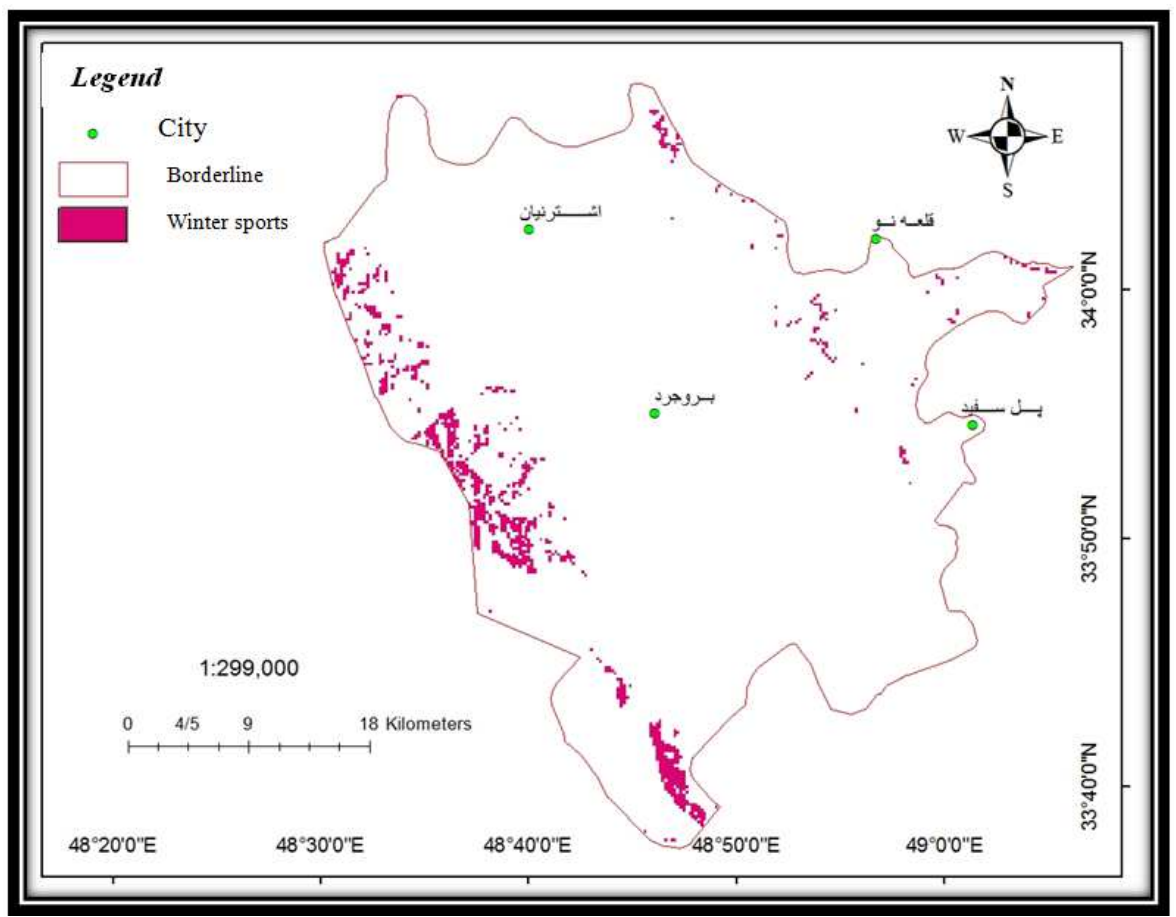

Picture 20. Map of suitable zones for winter sports (skiing and snow-craft) in Borujerd County. 


\section{Identification of Suitable Zones for Nature Walks and Natural Sightseeing}

Based on identified factors, nature walk and sightseeing covers the areas with nice vegetation and beautiful landscape, rivers and water resources. With 25750 ha area, Bazarjan region lies between $49^{\circ} 52^{\prime} \mathrm{E}$ and $50^{\circ} 2^{\prime} \mathrm{E}$ and between $34^{\circ} 43^{\prime} \mathrm{N}$ and $34^{\circ} 57^{\prime} \mathrm{N}$, and almost 2 kilometers away from Borujerd. It is a mountainous region with numerous hills in different elevations. Its highest peak belongs to Tova Mountain with 2396 meters height. Ghare-Chai River flows from west to the east of the region and creates a spectacular diversity of life in its path. The vegetation cover includes different kinds of Geramineae, Ferula Gummosa, Artemisia, and Astragal us. This area is also the natural habitat for different species of wild life such as Tup and Ewe, wild Goat, Wolf, Caracal, wild Boar, Hyena, Otter, Marten, Gray Partridge, Passerines and birds of prey. As of November $22^{\text {nd }} 2006$ this area was declared to be a no-hunting zone.

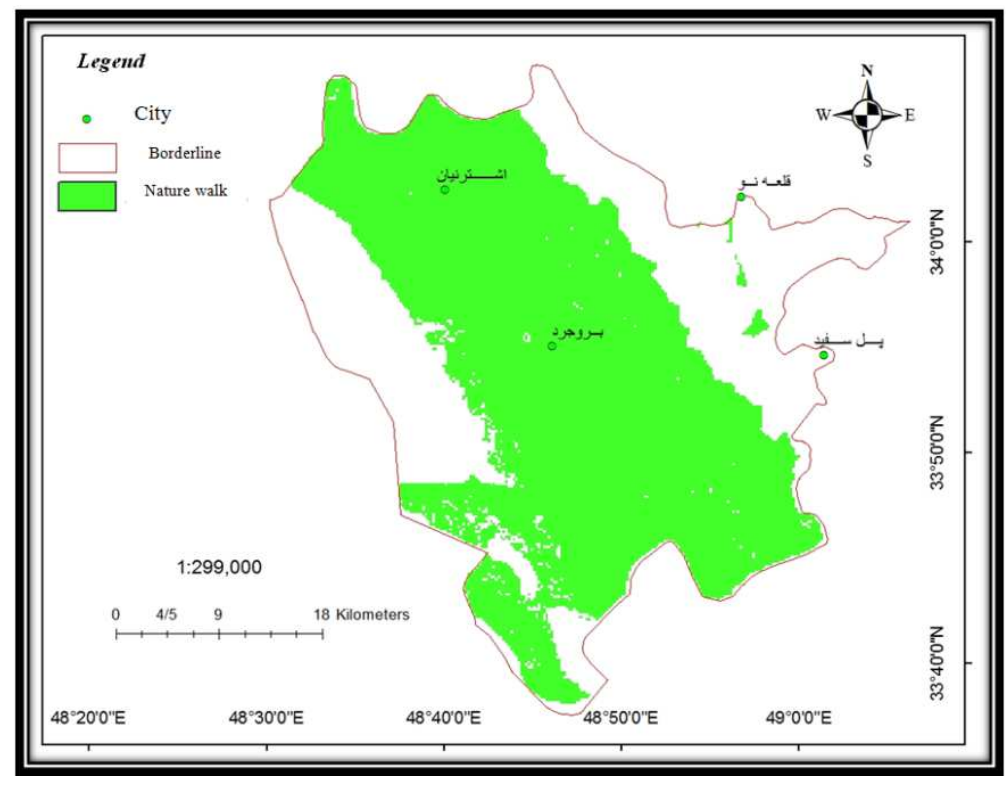

Picture 21. Map of suitable zones for nature walk and sightseeing in Borujerd County.

\section{Rural Tourism}

Villages and destinations for rural tourism are selected according to criteria such as water, electricity, telephone, and gas accommodations, population of more than 50 households, accessibility quality, historical and cultural attractions, preparedness of local authorities, cooperative companies, possibility of development of tourism for more than six months, roads and transportation, healthcare accessibility, positive public opinion, and similar other factors.

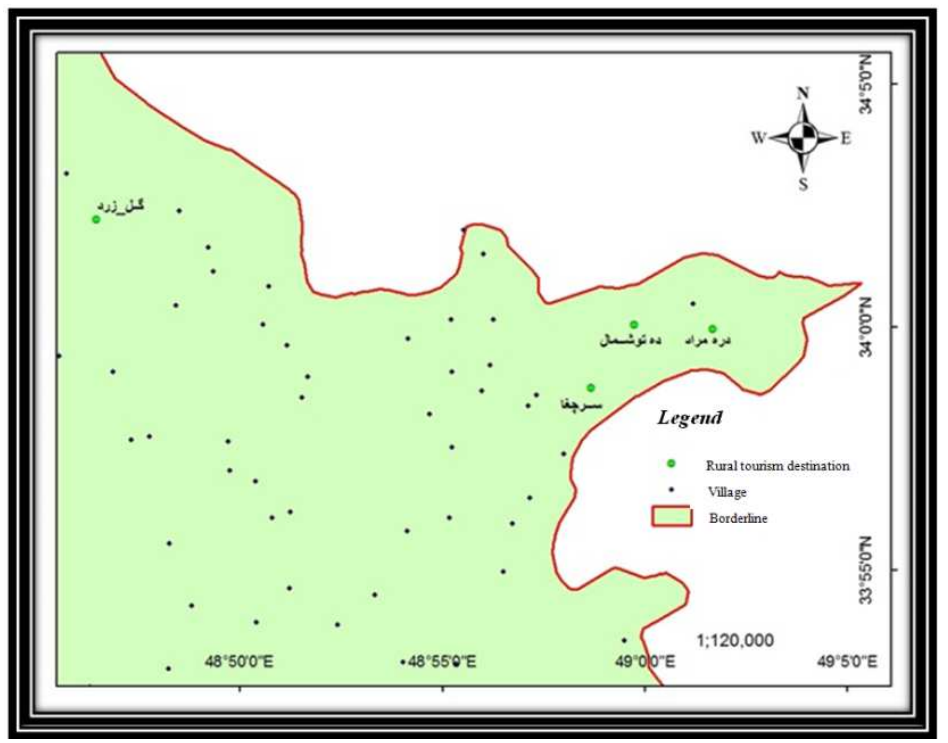

Picture 22. Map of rural tourism destinations in Borujerd County. 


\section{Presenting TOPSIS Model}

In TOPSIS model, potentials are considered as criteria and parameters such as slope, aspect, elevation, vegetation, climate, and temperature are considered as indicators. On that basis the TOPSIS matrix is created. In the end, the ranking order and prioritization of the alternatives using TOPSIS model has been carried out in the following manner.

The alternative with higher CL is more preferred.

Table 3. CLi value.

\begin{tabular}{ll}
\hline d Value & \\
\hline Zones & CLi value \\
\hline Hiking & 0.46193 \\
Mountaineering & 0.40834 \\
Winter sports & 0.396483 \\
Nature walk & 0.60567 \\
Rural tourism & 0.603314 \\
\hline
\end{tabular}

As a center of tourism, Borujerd is a large and historical county in Lorestan province. In this county, a set of tourist attraction in proportion to capabilities, capacities, and limitations of the attraction (cultural, historical, man-made, and ecotourism) and their position in tourism decisionmaking (region, area, district, and point) are specifically important. The main effective criteria in evaluation of potentials and prioritization of tourist attractions in the county have been mentioned and evaluated from ecological point of view. Investments should first focus on ecotourism, and after that on rural tourism; hiking, mountaineering, and winter sports have the next priority in a respective manner. Besides that, winter sports complexes and cable car systems should be developed and areas should be established as wildlife resorts for public use. Considering the great potentials of this region in terms of tourist attraction, livelihood of this important industry and its irreplaceable role in local development is a likely prospect.

In this context, by determining new tourism routes in different parts of the county fair distribution of opportunities and benefits of local community from development of tourism industry can be secured. Through appropriate marketing local attractions can be introduced to tourists. Alongside the marketing, creation of welfare accommodation and infrastructures can attract more tourists and provide grounds for employment of young workforce in tourism market and prevent migration of rural settlers to large cities.

\section{Problems of Tourism in the County}

- Lack of a consistent and comprehensive plan for tourism marketing is one of the major problems in the county.

- Lack of infrastructural accommodations in villages and important cities.

- Lack of a hospitable culture towards tourists in the county.

\section{Solutions}

- Devising a consistent and comprehensive plan by considering marketing parameters in order to develop tourism in Borujerd County.

- Establishment of infrastructures and required accommodations for rural tourism.

- Educating the local community on economic, cultural, and political benefits of tourism in order to make them more hospitable and cooperative toward the tourists.

\section{References}

[1] Rezvani A, 2002, ecotourism and its role in environmental protection, Tehran, political-economical information periodical, No.174

[2] Shakoui H, 1975, an introduction to tourism geography, Tabriz University

[3] Ranjbarian B, Zahedi M, 2005, identification of tourism, Chaharbagh, $1^{\text {st }}$ edition, Lorestan.

[4] Sante-Riveira, I., Crecente-Maseda, R. and Miranda- Barros, D., 2008. GIS-based planning support,system for rural landuse allocation. Computers and Electronics in Agriculture, 63: 257-273.

[5] Makhdoom, Majid, 2013, "Fundamental of Land Use Planning", Tehran university publication, 14 th edition.

[6] Tavalaei S, 2007, a survey of tourism industry, TarbiatMoalem University, $1^{\text {st }}$ edition, Tehran. 